\title{
Mechanical Properties of Soft Soil considering the Influence of Unloading Stress Paths
}

\author{
Wei Huang, ${ }^{1,2}$ Junjie Li, ${ }^{1}$ Yuming Lu $\mathbb{D}^{3},{ }^{3}$ Dongsheng Li, ${ }^{1}$ Yaqing Mou, ${ }^{1}$ Xuheng Wu, \\ Zhijian Jiang, ${ }^{4}$ and Ziyun $\mathrm{Li}^{1}$ \\ ${ }^{1}$ School of Civil Engineering and Architecture, Chongqing University of Science and Technology, Chongqing 401331, China \\ ${ }^{2}$ Chongqing Key Laboratory of Energy Engineering Mechanics \& Disaster Prevention and Mitigation, Chongqing 401331, China \\ ${ }^{3}$ School of Energy and Building Environment, Guilin University of Aerospace Technology, Guilin 541000, Guangxi, China \\ ${ }^{4}$ Shenzhen Water Planning \& Design Institute Co., Ltd., Shenzhen 518000, Guangdong, China
}

Correspondence should be addressed to Yuming Lu; luyuming@guat.edu.cn

Received 19 April 2020; Revised 14 January 2021; Accepted 5 April 2021; Published 22 April 2021

Academic Editor: Weerachart Tangchirapat

Copyright ( 2021 Wei Huang et al. This is an open access article distributed under the Creative Commons Attribution License, which permits unrestricted use, distribution, and reproduction in any medium, provided the original work is properly cited.

\begin{abstract}
The mechanical properties of soft soil are crucial for the design and construction of underground space excavation; however, the current design and numerical analysis of underground spaces consider the loading mechanical parameters, ignoring the influence of the unloading stress path resulting in frequent construction accidents in practice. Here, soft soil in Shenzhen, China, is taken as the research subject, and a series of consolidated-undrained unloading tests are performed. First, K0 consolidation is conducted. Then, unloading tests are performed with different unloading ratios to simulate different unloading stress paths. The test results show that the soft soil deformation characteristics are closely related to the stress path and unloading ratio. Under different unloading ratios, soft soil will undergo compression deformation or rebound deformation. Under unloading conditions, the deviator stress-strain curve satisfies a hyperbolic function and can be normalized with the average consolidation confining pressure. With the increase in the unloading ratio, the initial tangent modulus first decreases and then increases, the cohesion decreases, and the internal friction angle does not change significantly. The loading mechanical parameters are not suitable for numerical calculation in unloading engineering. In this paper, more unloading paths are considered, such as UU1.0 and UU0.5. The results of the study provide a theoretical basis for the calculation of the numerical analysis of the soil body at different depths in rich soft soil pits.
\end{abstract}

\section{Introduction}

As a region-specific soil with high water content, high compressibility, and low strength, soft soil is widely distributed in the coastal areas of Northern Europe, North America, and China $[1,2]$. Currently, with rapid urban development, large-scale underground spaces, such as underground train stations and shopping malls, have been constructed in these aforementioned areas. During the development of such underground spaces, many problems, such as soil deformation and instability, arise due to unloading excavation [3]. During this process, the unloading mechanical properties of soft soil are quite different from those under loading conditions [4]. For a long time, the soil strength and deformation parameters used in the numerical analyses of underground excavations in soft soil areas have been obtained through axial loading tests (conventional triaxial compression tests), neglecting the influence of the unloading stress paths on the soil strength and deformation parameters [5]. This will inevitably lead to a large difference between the theoretical calculation results and the actual engineering results of the stress and deformation [6]. Typically, the mechanical properties of soft soil are related to the unloading/loading stress paths [7]. Studies on mechanical properties under different unloading stress paths have engineering application value in the stress and deformation analysis of unloading excavation projects. They can significantly deepen the unloading theory research of soft soil.

From the aspect of the stress path, the mechanical properties of soft soil can be divided into loading mechanical properties and unloading mechanical properties. During 
early research, axial loading strength and deformation parameters were widely obtained and used in the numerical analysis of unloading engineering, resulting in large errors in theoretical calculation results and engineering accidents [8]. Currently, theoretical research shows that, in addition to the initial consolidation pressure, the mechanical properties of soft soil are closely related to the stress path [9, 10]; therefore, in the study of the unloading excavation process in soft soil areas, it has become a research consensus for scholars to consider the influence of the unloading stress path on the mechanical properties of the soft soil. A few unloading tests of soft soil carried out by several scholars pointed out that the stress paths can significantly affect the strength parameters of soft soil, and the unloading modulus of soft soil is much larger than the corresponding compression modulus obtained in triaxial tests [11]. In addition, the unloading strength of soft soil under lateral unloading conditions is lower than that obtained in conventional triaxial tests [12]. In terms of engineering applications, Zhou and Chen [13] pointed out that the calculation results obtained by replacing the unloading modulus with the loading modules are relatively dangerous. Concurrently, lateral unloading will lead to soil dilatation and lower the effective stress of the soil $[14,15]$.

Currently, the majority of studies still focus on the mechanical properties of soft soil under a lateral unloading stress path [16]. Zhang et al. [17] studied the influence of the stress path on the mechanical properties of soft soil under different unloading ratios $(R=1.5,2.0,4.0)$, pointing out that, under different unloading stress paths, the stress-strain curves of soil are obviously different, and the samples may undergo compression failure or rebound failure, which indicates that the failure mode of soil is sensitive to the stress path [18].

According to the analyses mentioned above, the stress processed in the soil mass is not a simple loading path, and different unloading stress paths are also involved and are even more complicated during the excavation of underground space in soft soil areas. However, the influence of the unloading stress path on changes in the mechanical properties of soft soils has not been systematically studied in detail. A series of triaxial tests were conducted with different unloading stress paths on the soft soil (Shenzhen, China) that has been selected in this study. The mechanical properties of the soft soil obtained through this experiment would benefit the numerical analysis and practical engineering design of the pit.

\section{Materials and Methods}

2.1. Stress Path and Unloading Ratio. Unloading paths that exist during the underground excavation in soft soil areas can be generally divided into three types, as shown in Figure 1. Stress path $a$ shows a stress state in which the lateral unloading of soil in the active area and the overlying pressure basically remain unchanged during the excavation of the underground space; that is, the axial stress $\sigma_{1}$ remains unchanged while the lateral stress $\sigma_{3}$ decreases. Stress path $b$ shows a stress state in which the axial stress and the lateral

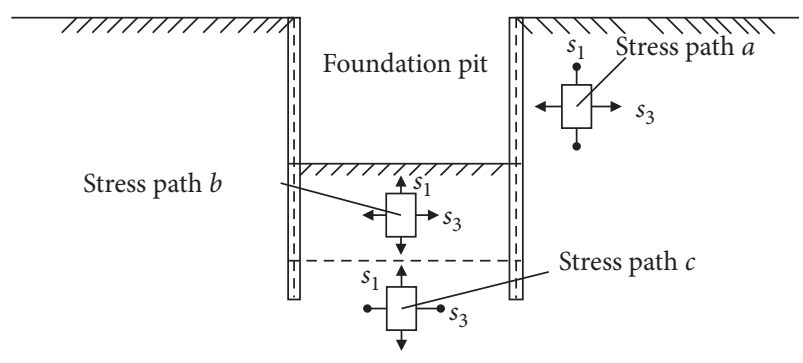

Figure 1: Distribution of stress paths.

stress in the shallow area below the excavation surface both decrease; that is, the axial stress $\sigma_{1}$ and the lateral stress $\sigma_{3}$ decrease. Stress path $c$ shows a stress state in which the axial stress decreases and the lateral stress remains unchanged in the deeper area below the excavation surface; that is, the axial stress $\sigma_{1}$ decreases while the lateral stress $\sigma_{3}$ remains unchanged.

To thoroughly study the influence of the three aforementioned unloading stress paths on the mechanical properties of soft soil, in this paper, UU-R and LU-R are used to describe the specific stress paths: UU refers to vertical unloading and horizontal unloading, $L U$ refers to vertical loading and horizontal unloading, and $R=\Delta \sigma_{1} / \Delta \sigma_{3}$ is the ratio of vertical stress variation $\Delta \sigma_{1}$ to horizontal stress variation $\Delta \sigma_{3}$. For example, UU0.5 means unloading in both vertical and horizontal directions at the same time, with an unloading ratio of $R=\Delta \sigma_{1} / \Delta \sigma_{3}=0.5$. Thus, UU0.0 represents stress path $a$; UUo represents stress path $c$; and LUo represents the stress path of conventional triaxial loading tests, used as the control group for all unloading stress paths UUR. According to situations that may be encountered in practical engineering, 6 different unloading ratios $(R=0.0,0.5,1.0,2.0,4.0$, and $\infty$, as shown in Figure 2) are applied to systematically study the unloading mechanical properties of soft soil.

2.2. Test Equipment and Soil. In the tests, a TSZ-2S fully automatic triaxial test apparatus (Figure 3) is used to carry out triaxial unloading tests and loading tests. This apparatus consists of a confining pressure system, a back pressure system, an axial loading system, and a measuring system. The measuring ranges of the axial pressure sensor, pressure chamber, and displacement sensor are $1 \mathrm{kN}, 2 \mathrm{MPa}$, and $50 \mathrm{~mm}$, respectively. The size of the standard soil sample is $80.0 \mathrm{~mm}$ in height and $39.1 \mathrm{~mm}$ in diameter.

The test soils are collected from a large foundation pit in Shenzhen, China; those soils are grayish-black, with a small number of shells and a fishy smell. The basic physical properties of the soil samples obtained via laboratory tests are shown in Table 1.

\subsection{Testing Process}

2.3.1. Saturation. Due to the low strength of the soft soil sample, it is easy to disturb the soil mass if the soil sample is loaded after vacuum saturation. Therefore, conventional vacuum saturation is eliminated, but after the sample is loaded, 


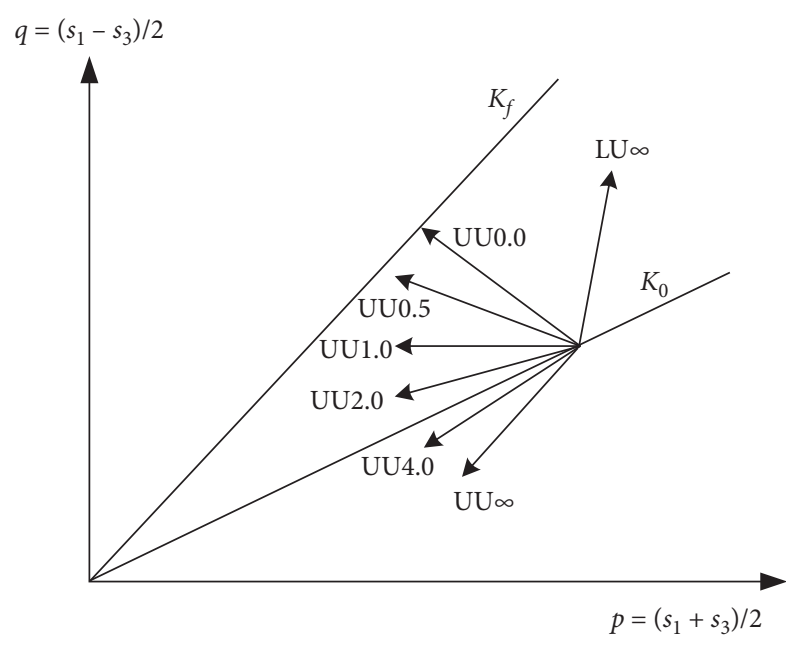

FIGURE 2: Stress paths and unloading ratios.

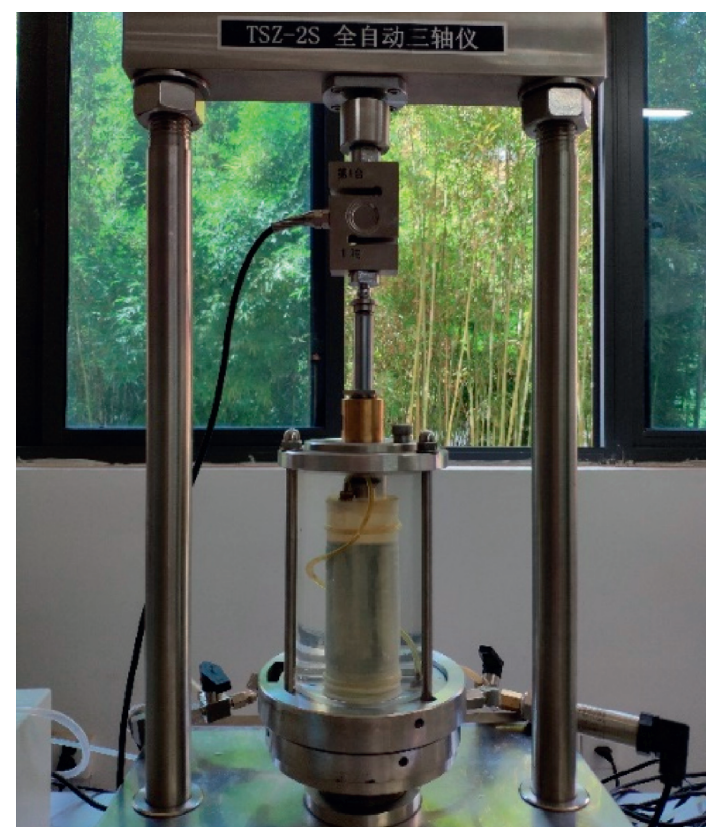

FIgURE 3: TSZ-2S fully automatic triaxial test apparatus.

TABle 1: Basic physical properties of the soft soil.

\begin{tabular}{lccccccc}
\hline$\rho\left[\mathrm{g} / \mathrm{cm}^{3}\right]$ & $w[\%]$ & $G_{\mathrm{s}}$ & $w_{\mathrm{L}}[\%]$ & $w_{\mathrm{p}}[\%]$ & $I_{\mathrm{p}}$ & $c[\mathrm{kPa}]$ & $\Phi\left[^{\circ}\right]$ \\
\hline 1.81 & 39.4 & 2.72 & 41.6 & 25.3 & 16.3 & 19.2 & 28.3 \\
\hline
\end{tabular}

back pressure saturation is carried out through the back pressure system of the triaxial test apparatus. During the back pressure saturation, the confining pressure is $20 \mathrm{kPa}$ higher than the back pressure. The test shows that after maintaining the confining pressure at $110 \mathrm{kPa}$ and the back pressure at $90 \mathrm{kPa}$ for 24 hours, Skempton's coefficient $B$ of the soil sample reaches 0.95 , indicating that the soil sample is saturated.

2.3.2. Consolidation. To simulate the self-weight stress state of the soil, a $K_{0}$ consolidation test is required before the unloading test. By using the $K_{0}$ consolidation control module $\left(K_{0}=0.53\right)$ of the TSZ-2S fully automatic triaxial test apparatus, the confining pressure is applied according to the test scheme shown in Table 2, with the axial pressure applied synchronously and automatically. The $K_{0}$ consolidation is deemed to be completed when the excess pore water pressure generated during consolidation dissipates to $0 \mathrm{kPa}$.

2.3.3. Setting of the Stress Path. According to the unloading ratio $R=\Delta \sigma_{1} / \Delta \sigma_{3}$ in Table 2, stress paths are set in the TSZ$2 S$ fully automatic triaxial test apparatus. During the unloading process, the confining pressure $\left(\sigma_{3}\right)$ of the soil sample decreases with an unloading rate of $10 \mathrm{kPa} / \mathrm{h}$ [17]; meanwhile, the axial pressure $\left(\sigma_{1}\right)$ simultaneously decreases according to the unloading ratio $R$ to simulate the unloading mechanical behavior of the soil. Furthermore, the stress path LU $\infty$ corresponds to a conventional triaxial loading test, and the axial pressure $\left(\sigma_{1}\right)$ increases with a rate of $10 \mathrm{kPa} / \mathrm{h}$.

2.3.4. Unloading Testing. Before unloading testing, the upper and lower drain valves of the triaxial apparatus are closed; then, the unloading test is carried out along a certain stress path UUR and LUo (Figure 2). After the deformation per hour is less than $0.01 \mathrm{~mm}$, the unloading deformation reaches a stable state. When unloading to a certain pressure level, if the strain rate increases sharply and the deformation cannot reach a stable state, the unloading test ends in failure. The confining pressure, axial pressure, axial deformation, and excess pore water pressure measurements of the soil sample were recorded automatically until the axial strain reaches $15 \%$.

\section{Results and Discussion}

3.1. Deviator Stress-Strain Curve. To analyse the law of soil deformation with different unloading stress paths, the relationship curve between the deviator stress and axial strain is drawn, as shown in Figure 4. According to the figure, the deviator stress-strain curve of soft soil is essentially hyperbolic function under both loading and unloading conditions. With changes in the stress path and unloading ratio, the deformation of the sample can be divided into compressive deformation and rebound deformation. Unloading stress paths (UU0.0, UU0.5) and loading stress path (LUD) correspond to compressive deformation, as shown in Figure 4(a) (since the corresponding deviator stress of stress path UU1.0 remains unchanged, it is not possible to plot the corresponding deviator stress-strain curve). Taking the consolidation confining pressure of $100 \mathrm{kPa}$ as an example, the failure stress at the unloading stress path (UU0.0, UU0.5) test is lower than that at the conventional triaxial loading stress path (LUo) test, which indicates that under unloading conditions, the deviator stress is more likely to cause excessive shear deformation in the soil. In addition, in the conventional triaxial loading test, the deviator stress keeps increasing as the strain increase, and the deviator stress-strain curve exhibits stronger strain hardening compared with that under unloading conditions. 
TABLE 2: Test plan of unloading/loading stress path.

\begin{tabular}{|c|c|c|c|}
\hline Stress path & $\begin{array}{l}\text { Confining pressure of } \\
\text { consolidation } \sigma_{3 c}[\mathrm{kPa}]\end{array}$ & $\begin{array}{c}\text { Axial pressure of } \\
\text { consolidation } \sigma_{1 \mathrm{c}}[\mathrm{kPa}]\end{array}$ & Unloading ratio $R$ \\
\hline UU0.0 & $100,200,300$ & $189,377,566$ & $R=\Delta \sigma_{1} / \Delta \sigma_{3}=0.0, \sigma_{3}$ decreases, while $\sigma_{1}$ remains unchanged \\
\hline UU0.5 & $100,200,300$ & $189,377,566$ & $R=\Delta \sigma_{1} / \Delta \sigma_{3}=0.5, \sigma_{3}$ and $\sigma_{1}$ decrease \\
\hline UU1.0 & $100,200,300$ & $189,377,566$ & $R=\Delta \sigma_{1} / \Delta \sigma_{3}=1.0, \sigma_{3}$ and $\sigma_{1}$ decrease \\
\hline UU2.0 & $100,200,300$ & $189,377,566$ & $R=\Delta \sigma_{1} / \Delta \sigma_{3}=2.0, \sigma_{3}$ and $\sigma_{1}$ decrease \\
\hline UU4.0 & $100,200,300$ & $189,377,566$ & $R=\Delta \sigma_{1} / \Delta \sigma_{3}=4.0, \sigma_{3}$ and $\sigma_{1}$ decrease \\
\hline UU⿻ & $100,200,300$ & $189,377,566$ & $R=\Delta \sigma_{1} / \Delta \sigma_{3}=\infty, \sigma_{3}$ remains unchanged, while $\sigma_{1}$ decreases \\
\hline LU⿻ & $100,200,300$ & $189,377,566$ & $R=\Delta \sigma_{1} / \Delta \sigma_{3}=\infty, \sigma_{3}$ remains unchanged, while $\sigma_{1}$ increases \\
\hline
\end{tabular}

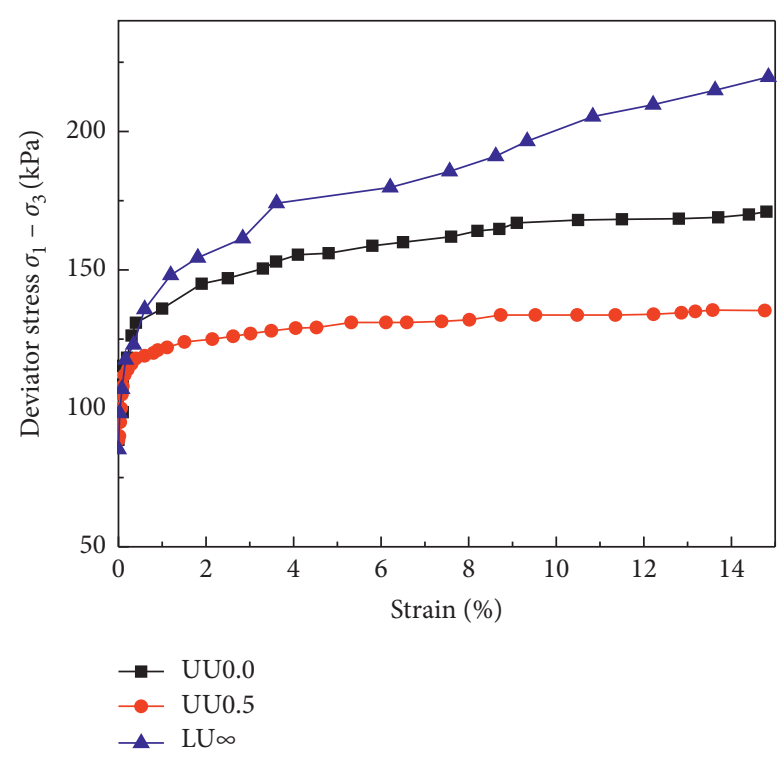

(a)

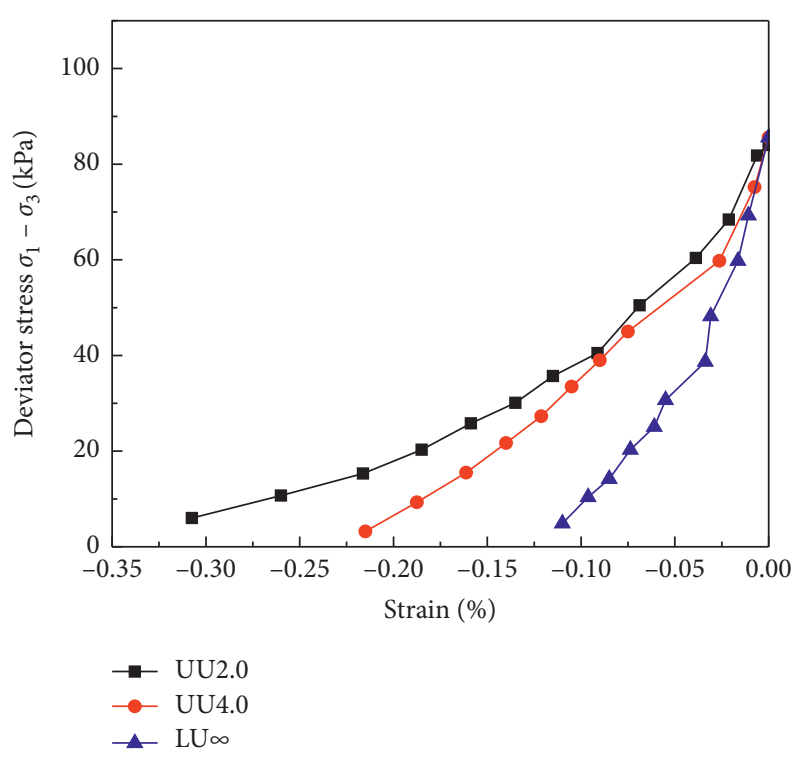

(b)

Figure 4: Deviator stress and axial strain $(100 \mathrm{kPa})$. (a) Deviator stress and compressive strain. (b) Deviator stress and rebound strain.

Along the unloading stress path, as the unloading ratio $R$ increases from 0.0 to 0.5 , the failure stress of the soft soil gradually decreases. The tendency of result is consistent with the finding by Liu and Hou [11], but the failure stress values are quite different. When the confining pressure reaches $100 \mathrm{kPa}$, the failure stress of the stress path UU0.0 is approximately $105 \mathrm{kPa}$ in the finding by Liu and Hou [11], while the failure stress in this study is approximately $174 \mathrm{kPa}$. Such inconsistencies could be due to the different initial consolidation conditions and the different regional mechanical properties of the soft soils in Shenzhen and Shanghai.

The unloading stress paths UU2.0, UU4.0, and UUD correspond to rebound deformation. As shown in Figure 4(b), the rebound deformation of soft soil increases with decreasing unloading ratio. The axial stress $\sigma_{1}$ in the test can be unloaded to a value only equal to the lateral stress $\sigma_{3}$, that is, the minimum value of the deviator stress $\sigma_{1}-\sigma_{3}$ is 0 . Compared with stress paths UU4.0 and UUD, the corresponding confining pressure of stress path UU2.0 is lower; thus, the rebound deformation is larger. Therefore, to reduce the rebound deformation of soil in unloading engineering, such as foundation pit excavation, control measures should be taken to avoid the reduction in soil confining pressure.

The deviator stress and axial strain relationship curves are drawn for different consolidation confining pressures in Figure 5. The deviator stress-strain curve exhibits strain hardening. With the increase in consolidation confining pressure, the initial slope of the deviator stress-strain curve becomes steeper, indicating that the initial tangent modulus gradually increases. Further analysis of the strain curve in Figure 5(a) shows that when the deviator stress accounts for $70 \%$ to $84 \%$ of the failure stress, the corresponding strain is only $0.8 \%$ to $1.0 \%$; that is, in the early unloading stage, considerable unloading does not cause a large axial strain of the soil mass, and a deformation lag arises. When $1.0 \%$ to $1.5 \%$ strain occurs, the strain of the soft soil can be gradually increased until unloading failure occurs under a small unloading load. This phenomenon indicates that the unloading failure of soft soil occurs suddenly during the unloading excavation of underground engineering. Especially after reaching $1.0 \%$ strain deformation, continuous unloading can lead to unloading failure of the soft soil. 


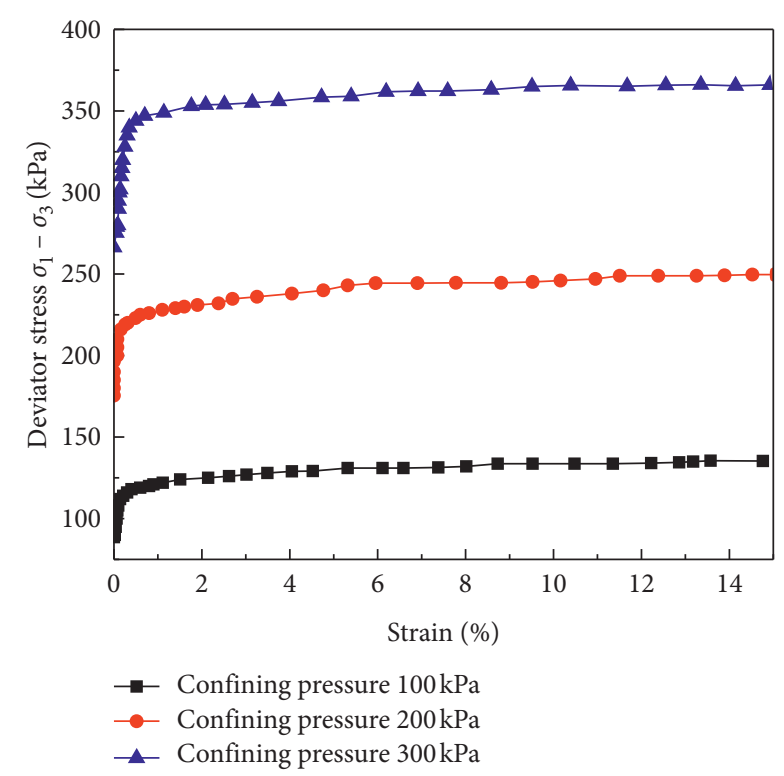

(a)

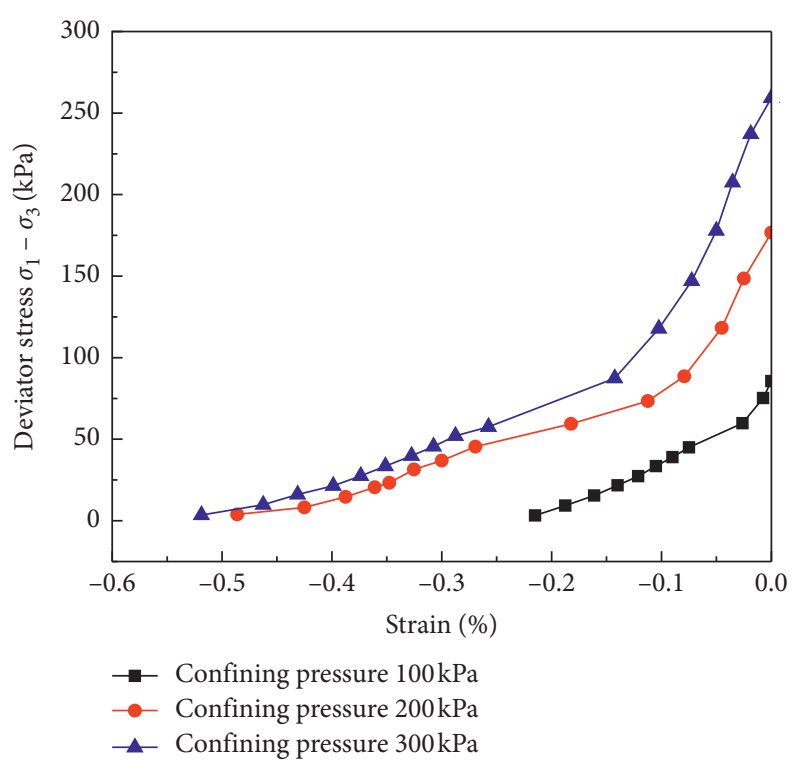

(b)

FIGURE 5: Deviator stress and axial strain under different consolidation confining pressures. (a) Stress path UU0.5. (b) Stress path UU4.0.

Figure 5(b) shows the deviator stress-strain curve of the UU4.0 stress path. The soft soil under this stress path shows rebound deformation. The deviator stress $(\sigma 1-\sigma 3)$ could not be unloaded to less than $0 \mathrm{kPa}$ due to the limitation of the test instrument so there is no failure occurring in the soil sample.

\subsection{Hyperbolic Fitting of Deviator Stress-Strain Relationship.} According to the above analysis, the deviator stress-strain curves of various stress paths of the studied soft soil are basically hyperbolic curves. Kondner [19] proposed that the following hyperbolic function can be used to represent the consolidated-undrained deviator stress-strain relationship of soft soil:

$$
\frac{\varepsilon}{\sigma_{1}-\sigma_{3}}=a+b \varepsilon
$$

In equation (1), $a$ is the intercept of the straight line and $b$ is the slope. By deduction, the initial tangent slope of the deviator stress-strain curve is $1 / a$, which is defined as the initial tangent modulus $E_{0}$; the slope is $b=1 /\left(\sigma_{1}-\sigma_{3}\right)_{\mathrm{ult}}$, and $\left(\sigma_{1}-\sigma_{3}\right)_{\mathrm{ult}}$ is the soil ultimate strength. In the K0 consolidation test, to eliminate the influence of the initial deviator stress $\left(\sigma_{1 \mathrm{c}}-\sigma_{3 \mathrm{c}}\right)$, equation (1) can be revised as follows:

$$
\frac{\varepsilon}{\left(\sigma_{1}-\sigma_{3}\right)-\left(\sigma_{1 c}-\sigma_{3 c}\right)}=a+b \varepsilon
$$

where $\sigma_{1 \mathrm{c}}$ and $\sigma_{3 \mathrm{c}}$ are the initial axial pressure and confining pressure during $K_{0}$ consolidation.

In the case of stress path UU0.0 and UU2.0, deviator stress-strain curves are drawn according to equation (2), as shown in Figure 6. Under different stress paths and different consolidation pressures, all the curves show a strong linear relationship, indicating that the test results can be well fitted with a hyperbolic curve through equation (2).
According to equation (2), the initial tangent modulus $E_{0}$ can be obtained by processing the test results of various stress paths. Due to space limitations in this paper, only $E_{0}$ for a consolidation confining pressure of $100 \mathrm{kPa}$ is listed, as shown in Table 3.

Table 3 shows that the initial tangent modulus $E_{0}$ first decreases and then increases with the increase in unloading ratio $R$. In general, the initial tangent modulus at the loading stress path LUo is significantly lower than that at the unloading stress path (UUR). In particular, at the stress path UUœ, the soil sample undergoes unloading rebound deformation only, and its initial tangent modulus is 18.8 times that of stress path LUo.

In this study, the variation pattern of the initial tangent modulus with unloading ratio is approximately the same as the conclusion obtained by Zheng [20]. In their study, the initial tangent modulus of UU0.0, UU2.0, UU4.0, and UUD unloading stress paths increases with the increase of the unloading ratio, which is consistent with the conclusion of this paper. However, this paper also investigated the UU0.5 unloading stress path, and it can be seen from Figure 4(a) that, under the same bias stress, the deformation of soft soil under the UU0.5 unloading stress path is slightly larger than that under the UU0.0 unloading stress path, so the initial tangent modulus under the UU0.5 unloading stress path is lower than that under the UU0.0 stress path. In addition, the failure ratio $R_{\mathrm{f}}$ and unloading ratio $R$ are not strongly correlated, but the failure ratio $R_{\mathrm{f}}$ generally exceeds 0.90 .

\subsection{Normalization of the Deviator Stress-Strain Relationship.} According to the deviator stress-strain curve in Figure 5, given the same type of stress path, the shapes of stress-strain curves under different consolidation pressures are basically similar, which indicates the possibility of normalization of the deviator stress-strain curves of soil samples. By 


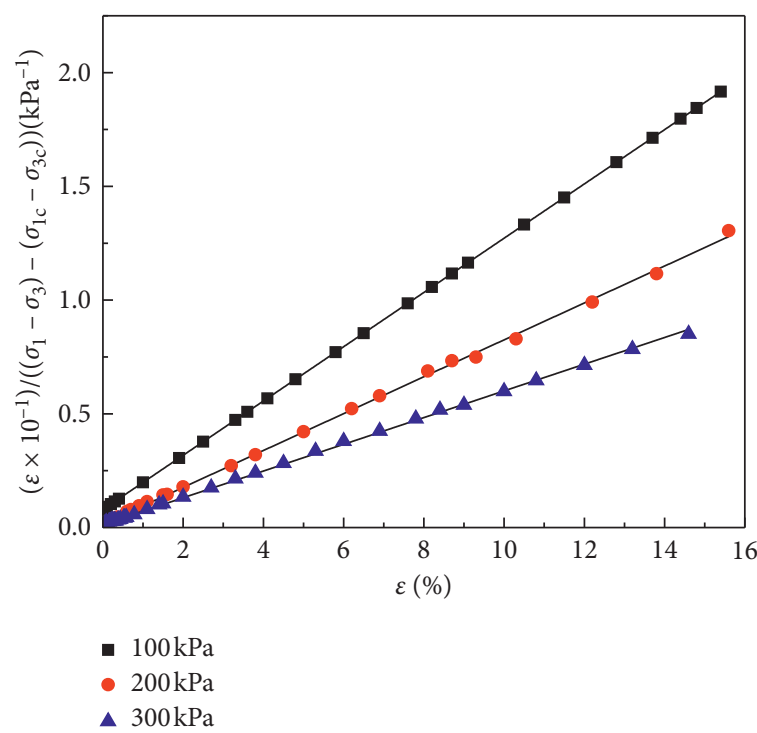

(a)

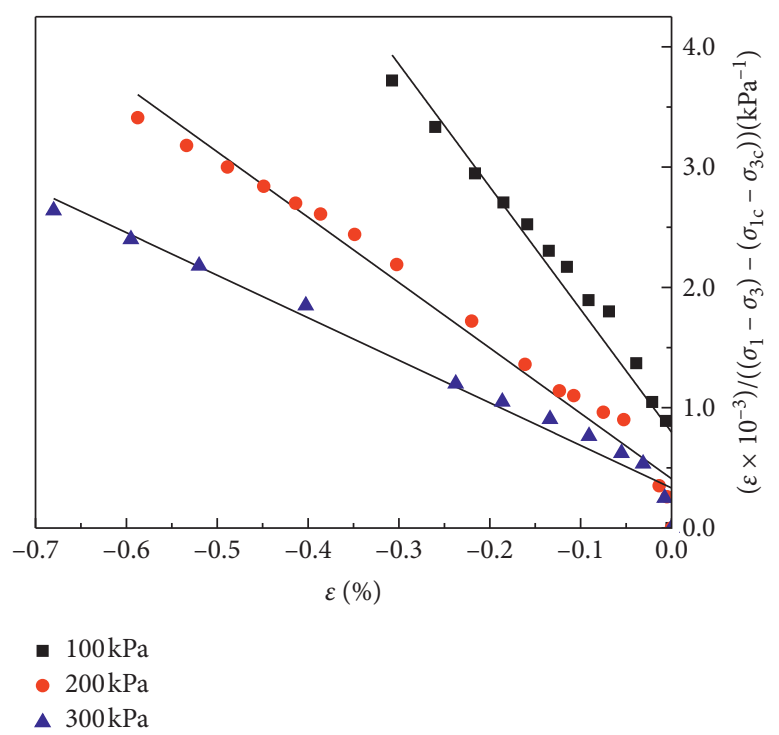

(b)

FIgURE 6: Hyperbolic functions of the deviator stress-strain relationships. (a) Stress path UU0.0. (b) Stress path UU2.0.

TABLE 3: Initial tangent modulus of soft soil under different stress paths $(100 \mathrm{kPa})$.

\begin{tabular}{|c|c|c|c|c|c|}
\hline Stress path & $a\left[\mathrm{MPa}^{-1}\right]$ & Initial tangent modulus $E_{0}[\mathrm{MPa}]$ & $b\left[\mathrm{kPa}^{-1}\right]$ & Ultimate strength $\left(\sigma_{1}-\sigma_{3}\right)_{\mathrm{ult}}[\mathrm{kPa}]$ & $R_{\mathrm{f}}^{\mathrm{a}}$ \\
\hline UU0.0 & 0.0791 & 12.64 & 0.0119 & 83.82 & 0.99 \\
\hline UU0.5 & 0.0932 & 10.73 & 0.0214 & 46.66 & 0.98 \\
\hline UU1.0 & 0.0144 & 69.49 & 0.0100 & 100.00 & 0.99 \\
\hline UU2.0 & 0.0080 & 125.00 & 0.0102 & 98.04 & 0.92 \\
\hline UU4.0 & 0.0057 & 175.44 & 0.0105 & 95.24 & 0.87 \\
\hline UUळ & 0.0053 & 188.68 & 0.0072 & 138.89 & 0.94 \\
\hline LUめ & 0.0997 & 10.03 & 0.0077 & 129.87 & 0.97 \\
\hline
\end{tabular}

${ }^{\mathrm{a}} R=\left(\sigma_{1}-\sigma_{3}\right) /\left(\sigma_{1}-\sigma_{3}\right)$ ult is the failure ratio.

normalizing the average consolidation confining pressure $\sigma_{\mathrm{m}}$, equation (2) can be revised as follows:

$$
\frac{\varepsilon \sigma_{\mathrm{m}}}{\left(\sigma_{1}-\sigma_{3}\right)-\left(\sigma_{1 c}-\sigma_{3 c}\right)}=\bar{a}+\bar{b} \varepsilon
$$

where $\sigma_{\mathrm{m}}$ is the average consolidation pressure and $\bar{a}$ and $\bar{b}$ are the intercept and slope of the normalized straight line, respectively.

According to equation (3), a normalized hyperbolic function representing the deviator stress-strain curve is drawn in Figure 7. For the same type of stress path, the deviator stress-strain curve of the soft soil shows a normalized characteristic. Overall, the normalized degree and regularity are good, but there is still a certain degree of dispersion, which may be caused by the inhomogeneity of the soil and the errors generated during the test operations.

3.4. Unloading Strength Parameters. According to Figure 4(a), for different unloading stress paths, the deformation parameters and failure stress of soft soil are different, which inevitably leads to the strength parameters of soft soil. In engineering practice, the unloading strength parameter of soft soil is very important for the stability calculation of underground spaces; therefore, the strength envelope of the soil sample is shown in Figure 8 (the strength parameter of a soil sample with rebounded deformation is not considered).

According to the figure, for the unloading stress paths of UU0.0, UU0.5, and UU1.0, the unloading ratio $R$ has little influence on the internal friction angle under total stress, but with the increase in unloading ratio, the cohesion decreases from $36.9 \mathrm{kPa}$ to $12.2 \mathrm{kPa}$, as shown in Figures $8(\mathrm{a})-8(\mathrm{c})$. The cohesion decreases with the increase of the unloading ratio. However, in the stress paths of UU2.0 and UU4.0, since the deviator stress $(\sigma 1-\sigma 3)$ cannot reach below $0 \mathrm{kPa}$ and the soil has not yet reached the destruction conditions, the strength envelope cannot be plotted and the strength parameters under the stress paths UU2.0 and UU4.0 cannot be summarized. In the control test of the unloading experiments, the cohesion of the conventional triaxial loading stress path LUD is $50.6 \mathrm{kPa}$, which is much higher than that of an unloading stress path and consistent with the finding by Zhou and Chen [21]. Because the axial compression of soil in the loading test is greater than its lateral expansion in the unloading test, the soil particles become increasingly denser, which results in increased cohesion.

Zhang [17] completed unloading drainage tests with unloading ratios $R$ of $0.0,1.0$, and 1.5 , the study pointed out 


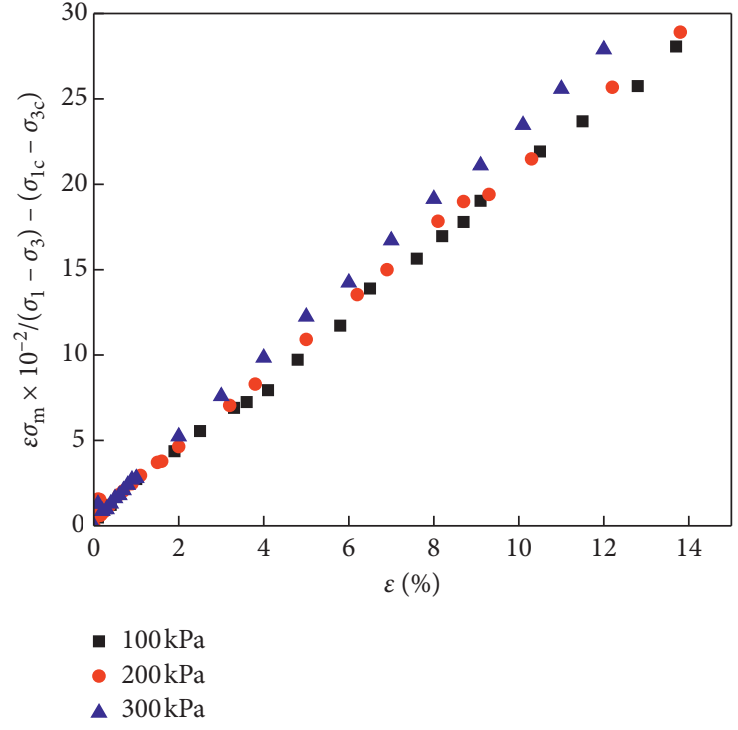

(a)

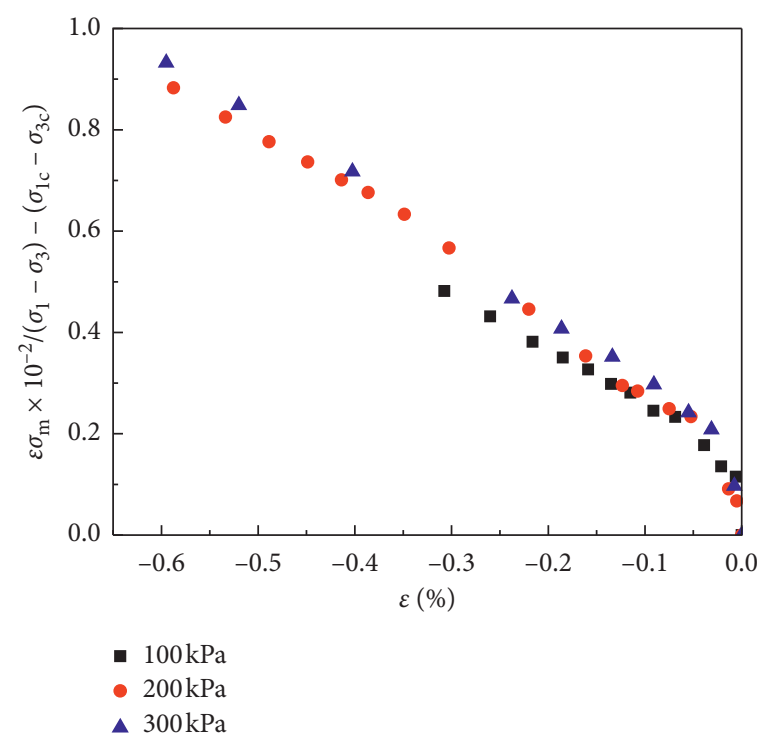

(b)

Figure 7: Normalization of deviator stress-strain. (a) Stress path UU0.0. (b) Stress path UU2.0.

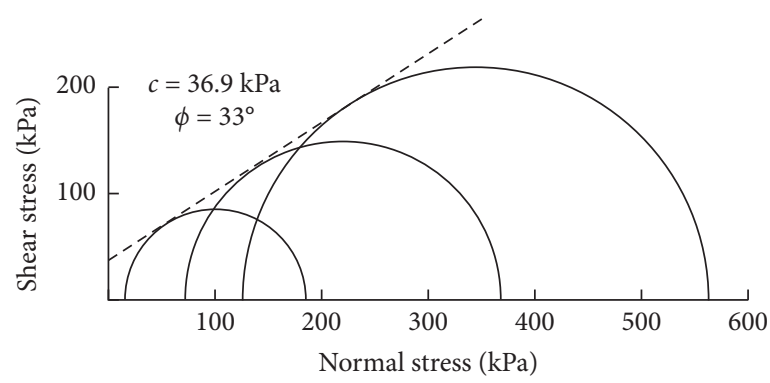

(a)

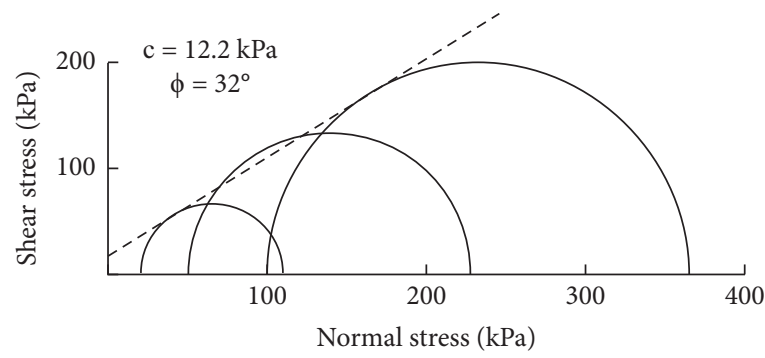

(c)

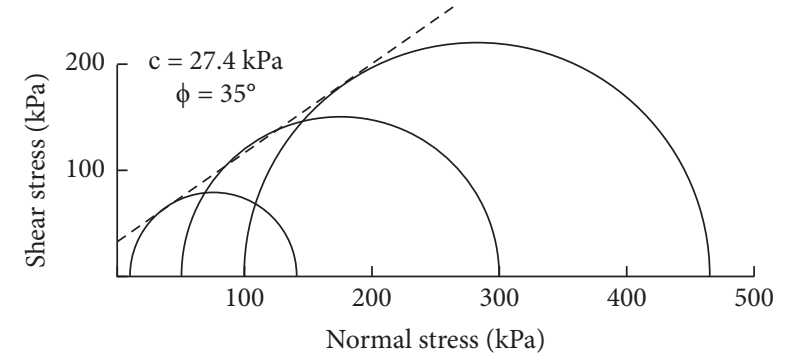

(b)

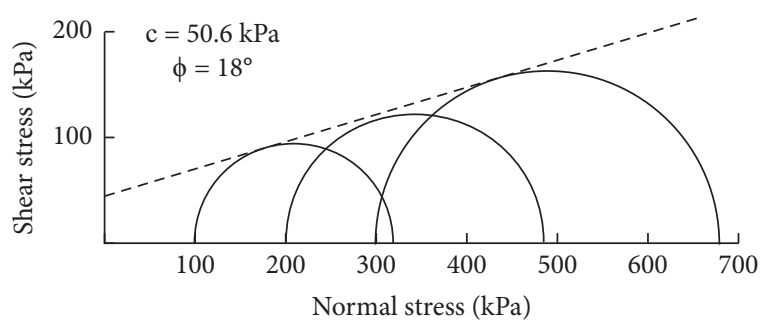

(d)

FiguRE 8: Strength envelope for different stress paths. (a) Stress path UU0.0. (b) Stress path UU0.5. (c) Stress path UU1.0. (d) Stress path LUळ.

that the effective stress strength parameters measured by different stress paths did not differ significantly $(c=2.6-4.1$; $\varphi=36.5-38.1^{\circ}$ ), and their findings basically satisfied the principle of effective stress. However, in this paper, the soft soil strength index parameters under the total stress strength are obtained by the consolidated-undrained unloading test, the study shows that the cohesion of soft soil gradually decreases with increasing unloading ratio $R$, and the internal friction angle changes only slightly, which is different from the results of Zhang [17]. The reason for this is that the excess pore water pressure generated during the consolidated-undrained unloading test plays a lubricating role on the soft soil, the soft soil under the stress path of this paper undergoes obvious shear expansion damage, and its lateral expansion is greater than the axial compression, which eventually leads to a reduction in cohesion.

3.5. Excess Pore Water Pressure. In this paper, since the unloading test and the conventional triaxial loading test are undrained tests, excess pore water pressure will be generated during these tests. The change in excess pore water pressure 


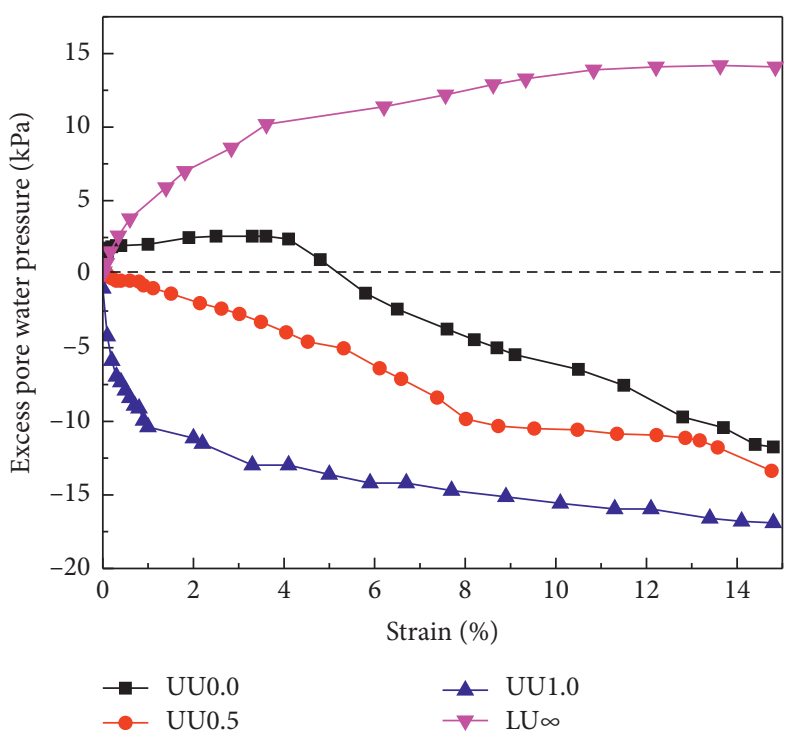

(a)

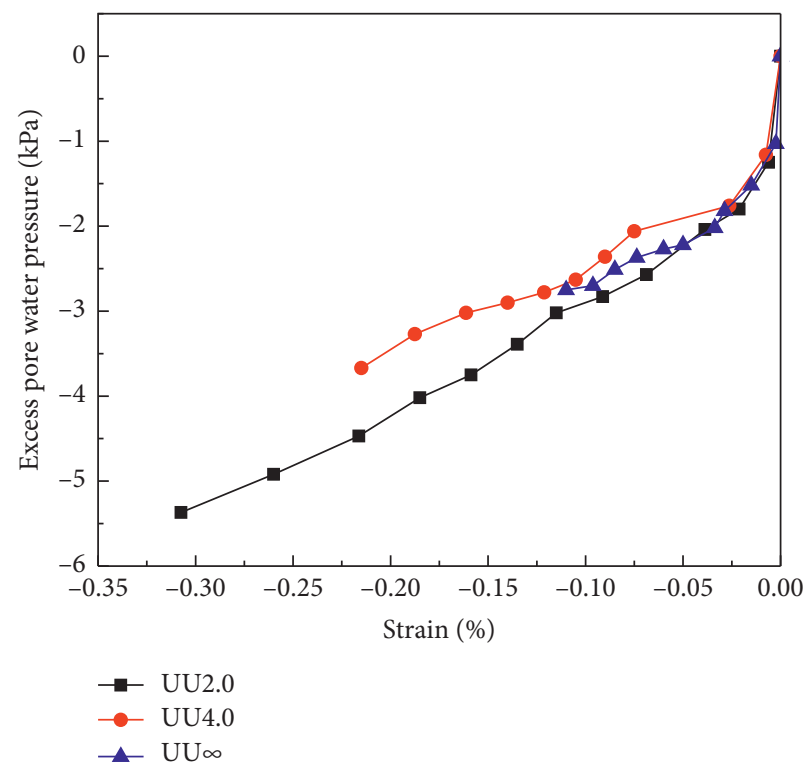

(b)

Figure 9: Strain and excess pore water pressure. (a) Compressive strain and excess pore water pressure. (b) Rebound strain and excess pore water pressure.

is very important for the analysis of volume change during soft soil failure. The changes in excess pore water pressure corresponding to compressive deformation and rebound deformation are shown in Figure 9. Under the conditions of loading and unloading, the overall development of excess pore water pressure is clearly different. At the loading stress path LUD, the excess pore water pressure increases because the axial compression of the soil is greater than its lateral expansion, resulting in sample volume reduction. This conclusion is consistent with Xiong et al. [22], but they only focus on unloading stress paths LUD and UU1.0. The unloading stress paths UU0.0, UU0.5, and UU1.0 were also evaluated in this study. The lateral expansion of the soil is greater than its axial compression so that the volume of the soil sample increases, which results in the overall decrease in excess pore water pressure.

For the unloading stress paths UU2.0, UU4.0, and UUD, soil rebound deformation is generated. The volume of the soil sample gradually increases, resulting in excess pore water pressure, as shown in Figure 9(b). The absolute value of excess pore water pressure increases with increasing rebound deformation but remains less than the absolute value of excess pore water pressure for the stress paths UU0.0, UU0.5, and UU1.0, which is caused by the different failure modes of the soft soil due to the different unloading stress paths.

The deviator stress-strain curves under all unloading conditions show strain hardening. Under the same stress path, the deviator stress-strain curve of soft soil has normalized characteristics. When the soft soil is in compressive deformation, both the cohesion and the absolute value of the excess pore pressure increase with the unloading ratio. However, due to the limitation of the testing device, the soil sample did not have any unloading strength parameters available in UU 2.0 and UU4.0 stress path. In the future study, the author will modify the instrument to apply negative deviator stress $(\sigma 1-\sigma 3)$ on soil samples and investigate the unloading strength parameter of testing soil.

\section{Conclusion}

By using a TSZ fully automatic triaxial test apparatus, a series of undrained triaxial unloading tests on soft soil from Shenzhen, China, were carried out with different unloading stress paths, and systematic studies on the unloading mechanical properties of soft soil were performed. In this paper, more stress paths (UU1.0, UU0.5, etc.) are discussed to obtain parameters such as unloading strength of soft soil under different stress paths; the results found that the unloading strength and initial tangent modulus under UU0.5 stress path are the lowest, and the parameters obtained under UU0.5 stress path are safer to be used in the calculation of numerical analysis of the foundation pit. The following conclusions were drawn:

(1) The deformation characteristics of the soft soil are closely related to the stress path, unloading ratio, and consolidation confining pressure. Under unloading conditions, the magnitude of the unloading ratio has an important influence on the shape of the stressstrain curve, initial tangent modulus, and failure stress of the soft soil. For different unloading stress paths, the sample may undergo compressive deformation or rebound deformation.

(2) For the unloading stress path, the deviator stressstrain curve of the soft soil shows strain hardening and can be fitted through hyperbolic functions. 
Normalization can be carried out with the average consolidation confining pressure.

(3) The strength parameters under unloading conditions are obviously different from those under loading conditions. In the stress paths of UU0.0, UU0.5, and UU1.0, the effect of the unloading ratio on the internal friction angle is insignificant, but the cohesion decreases with the increase of the unloading ratio. The stress parameters under unloading conditions should be adopted to calculate unloading rebound in underground spaces.

\section{Data Availability}

All the data presented in this paper are available from the authors.

\section{Conflicts of Interest}

The authors declare that they have no conflicts of interest.

\section{Acknowledgments}

This work was funded by the National Natural Science Foundation of China (no. 51908097); Natural Science Foundation of Chongqing (nos. cstc2019jcyj-msxmX0258 and cstc2020jcyj-msxmX0558); Chongqing University of Science and Technology Research Program (nos. ck2017zkyb013 and ck2017zkyb010); and Science and Technology Innovation Project of Chongqing University of Science and Technology (nos. YKJCX1920609 and YKJCX1920610). At the same time, the authors would also like to thank Professor Mijia Yang for polishing of this paper.

\section{References}

[1] W. Liu, M. Shi, L. Miao, L. Xu, and D. Zhang, "Constitutive modeling of the destructuration and anisotropy of natural soft clay," Computers and Geotechnics, vol. 51, pp. 24-41, 2013.

[2] W. Huang, K. J. Wen, D. S. Li et al., "Experiment study of lateral unloading stress path and excess pore water pressure on creep behavior of soft soil," Advances in Civil Engineering, vol. 2019, Article ID 9898031, 9 pages, 2019.

[3] Q. Jiang, X. P. Liu, F. Yan, Y. Yang, D. P. Xu, and G. L. Feng, "Failure performance of 3DP physical twin-tunnel model and corresponding safety factor evaluation," Rock Mechanics and Rock Engineering, vol. 54, no. 6, pp. 1-20, 2021.

[4] Y. G. Zhang, K. Y. Zhang, and Q. Z. Shi, "Research method of constitutive model for excavation unloading soil mass," Journal of Water Resources and Architectural Engineering, vol. 8, no. 4, pp. 40-43, 2010.

[5] A. Soltani, A. Deng, A. Taheri, M. Mirzababaei, and M. Jaksa, "A dimensional description of the unconfined compressive strength of artificially cemented fine-grained soils," Journal of Adhesion Science and Technology, vol. 34, no. 6, pp. 1-25, 2020.

[6] P. Ni, G. Mei, Y. Zhao, and H. Chen, "Plane strain evaluation of stress paths for supported excavations under lateral loading and unloading," Soils and Foundations, vol. 58, no. 1, pp. 146-159, 2018.
[7] Y. J. Cui, X. P. Nguyen, A. M. Tang, and X. L. Li, “An insight into the unloading/reloading loops on the compression curve of natural stiff clays," Applied Clay Science, vol. 83-84, pp. 343-348, 2013.

[8] C. S. Desai, S. Sane, and J. Jenson, "Constitutive modeling including creep-and rate-dependent behavior and testing of glacial tills for prediction of motion of glaciers," International Journal of Geomechanics, vol. 11, no. 6, pp. 465-476, 2010.

[9] T. Nagaraj, M. Murthy, and A. Sridharan, "Incremental loading device for stress path and strength testing of soils," Geotechnical Testing Journal, vol. 4, no. 2, pp. 74-78, 1981.

[10] R. H. Wang, J. L. Li, Y. Z. Jiang, X. Chen, and Y. Wang, "Experimental study of influence of excavation unloading on mechanical properties of sandstone," Rock and Soil Mechanics, vol. 31, no. S1, pp. 156-162, 2010.

[11] G. B. Liu and X. Y. Hou, "Residual stress analysis method of foundation pit in soft soil foundation pit," Underground Engineering and Tunnels, vol. 14, no. 2, pp. 2-7, 1996.

[12] W. F. Zheng, L. T. Shao, and J. Q. Jia, "Experimental research on simulated foundation excavation unloading process based on digital image processing technique," Journal of Dalian University of Technology, vol. 6,, pp. 851-855, 2008.

[13] Q. J. Zhou and X. P. Chen, "Research on rheological properties of soft clay under typical pit unloading paths," Rock and Soil Mechanics, vol. 34, no. 5, pp. 1299-1305, 2013.

[14] L. L. Zeng and X. P. Chen, "Analysis of mechanical characteristics of soft soil under different stress paths," Rock and Soil Mechanics, vol. 30, no. 5, pp. 1264-1270, 2009.

[15] H. Tanaka, A. Tsutsumi, and T. Ohashi, "Unloading behavior of clays measured by CRS test," Soils and Foundations, vol. 54, no. 2, pp. 81-93, 2014.

[16] P.-G. Hsieh, C.-Y. Ou, and H.-T. Liu, "Basal heave analysis of excavations with consideration of anisotropic undrained strength of clay," Canadian Geotechnical Journal, vol. 45, no. 6, pp. 788-799, 2008.

[17] K. Y. Zhang, G. S. Li, X. H. Mei, and W. Du, "Stressdeformation characteristics of silty soil based on $\mathrm{KO}$ consolidation and drainage unloading stress path tests," Chinese Journal of Geotechnical Engineering, vol. 39, no. 7, pp. 1182-1188, 2017.

[18] Z. Q. Sheng and T. Cui, "Engineering characteristics of foundation soil under the action of stress path of foundation pit excavation," Building Science, vol. 34, no. 7, pp. 1-11, 2018.

[19] R. L. Kondner, "Hyperbolic stress-strain response: cohesive soils," Journal of the Soil Mechanics and Foundations Division, vol. 89, no. 1, pp. 115-143, 1963.

[20] G. Zheng, Z. X. Yan, H. Y. Lei, and P. Wang, "Experimental studies on unloading deformation properties of silty clay of first marine layer in Tianjin urban area," Rock and Soil Mechanics, vol. 29, no. 5, pp. 1237-1242, 2008.

[21] Q. J. Zhou and X. P. Chen, "Test research on typical mechanical characteristics of soft clay under lateral unloading condition," Chinese Journal of Rock Mechanics and Engineering, vol. 28, no. 11, pp. 2215-2221, 2009.

[22] C. F. Xiong, L. W. Kong, and A. W. Yang, "Correlation between mechanical properties of marine soft clay and stress path," Chinese Journal of Geotechnical Engineering, vol. 35, no. S2, pp. 341-345, 2013. 